\title{
A direct sulfhydrylation pathway is used for methionine biosynthesis in Pseudomonas aeruginosa
}

\author{
M. Foglino, † F. Borne, M. Bally, † Gall $†$ and J. C. Patte
}

Author for correspondence: M. Foglino. Tel: +3391164490. Fax: +3391712124.

Laboratoire de Chimie Bactérienne, Centre National de la Recherche Scientifique, 31, Chemin Joseph Aiguier, 13402, Marseille Cedex 20, France

\begin{abstract}
The relationship between genes and enzymes in the methionine biosynthetic pathway has been studied in Pseudomonas aeruginosa. The first step is catalysed by an 0-succinylhomoserine synthase, the product of the metA gene mapped at $\mathbf{2 0} \mathrm{min}$ on the chromosome. The second step is achieved by direct sulfhydrylation, involving the enzyme encoded by a met $Z$ gene that we have identified and sequenced, located at $\mathbf{4 0} \mathbf{~ m i n}$. Thus Pseudomonas appears to be the only organism so far described that uses O-succinylhomoserine as substrate for a direct sulfhydrylation. As in yeast, the two transsulfuration pathways between cysteine and homocysteine, with cystathionine as an intermediate, probably exist in parallel in this organism.
\end{abstract}

Keywords: methionine biosynthesis, Pseudomonas, sulfhydrylation

\section{INTRODUCTION}

The biosynthetic pathway leading to methionine has been studied in many organisms and presents several characteristics that are interesting from an evolutionary point of view, as differences are apparent when different organisms are compared (see Fig. 1).

The first step, acylation of homoserine, is common to all organisms, but differs in the acyl group transferred. In enteric bacteria, the reaction is a succinylation (catalysed by a homoserine $O$-succinyltransferase, the product of the met $A$ gene in Escherichia coli; Michaeli \& Ron, 1981); it has been shown to be an acetylation by acetyl-CoA in Saccharomyces cerevisiae (homoserine O-acetyltransferase; the MET2 gene product; Langin et al., 1986) and in Brevibacterium flavum (Ozaki \& Shiio, 1982), whereas in plants $O$-phosphorylhomoserine has been identified as the natural form of activated homoserine (Macnitol et al., 1981). The last step is also similar among different species, a methionine synthase activity converting homocysteine to methionine (catalysed in E. coli by the products of the metE and metH genes; Chu et al., 1985; Greene et al., 1973).

\footnotetext{
† Present address: Laboratoire d'Ingéniérie et Dynamique des Systèmes Membranaires, Centre National de la Recherche Scientifique, 31, Chemin Joseph Aiguier, 13402, Marseille Cedex 20, France.
}

Abbreviation: PLP, pyridoxal 5-phosphate.

The GenBank/EMBLDDBJ accession number for the nucleotide sequence data reported in this paper is U10904.
The major differences depend upon the way the assimilation of the sulfur atom into the amino acid backbone is achieved and the way the so-called transsulfuration pathway occurs (for review, see Yamagata, 1989). Sulfur can be incorporated into a three-carbon derivative (a serine ester) yielding cysteine, or into a four-carbon derivative (a homoserine ester) yielding homocysteine. Homocysteine and cysteine can then be converted into one another by transsulfuration, which transfers the sulfur atom with the intermediary formation of cystathionine. Synthesis of cysteine from homocysteine (the C4 to C3 pathway) is the only pathway that exists in mammals. In enteric bacteria, the C3 to C4 pathway operates from cysteine and the homoserine ester; cystathionine $\gamma$ synthase (the $E$. coli met $B$ gene product; Duchange et al., 1983 ) and cystathionine $\beta$-lyase (the $E$. coli met $C$ gene product; Belfaiza et al., 1986) are successively involved (Fig. 1a). Yeast (Cherest \& Surdin-Kerjan, 1992) and B. flavum (Ozaki \& Shiio, 1982) are capable of incorporating reduced sulfur into the homoserine ester by direct sulfhydrylation, a reaction catalysed by an acetylhomoserine sulfhydrylase (the MET25 gene product in $S$. cerevisiae; Kerjan et al., 1986); homocysteine is then the precursor of both methionine and cysteine, C4 to C3 transsulfuration being the only pathway used to synthesize cysteine in yeast. Moreover, in S. cerevisiae (Fig. 1b) it has been shown that the reverse trassulfuration pathway exists in parallel, since a MET25 mutant can grow on cysteine as a source of methionine (Kerjan et al., 1986).

In Pseudomonas aeruginosa, somewhat contradictory results are reported in the literature. Calhoun \& Feary (1969) 
(a)
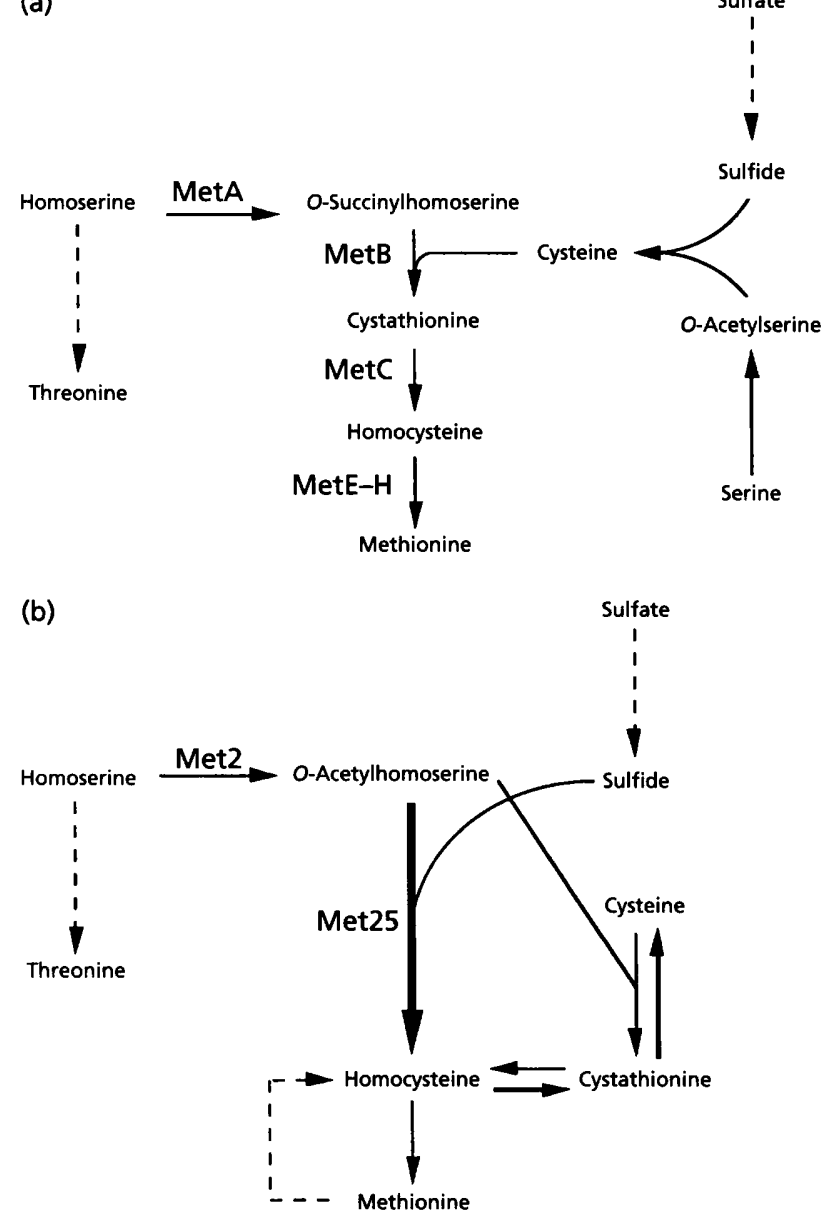

Fig. 1. The methionine biosynthetic pathway in (a) E. coli and (b) S. cerevisiae.

have isolated and characterized methionine and cysteine auxotrophs. The growth requirements of these mutants suggested to the authors that the route used was similar to the one described for E. coli. Gunther et al. (1979) and Schelenz et al. (1986) isolated mutants in the different steps of sulfate assimilation; the growth requirement of these mutants could be satisfied by methionine alone, whereas no strict cysteine auxotroph could be isolated. This result suggests the possibility of interconversion of these two amino acids.

In order to obtain a better understanding of the situation, we have undertaken a more precise identification of two mutations mapped on the $P$. aeruginosa chromosome (met28 and met-9011, located at 20 and $40 \mathrm{~min}$, respectively; O'Hoy \& Krishnapillai, 1987) and have obtained evidence for the involvement of an $\mathrm{O}$-succinylhomoserine sulfhydrylase in methionine biosynthesis in $P$. aeruginosa.

\section{METHODS}

Bacterial strains, plasmids and growth conditions. The bacterial strains and plasmids used are listed in Table 1. Bacteria were grown as described previously (Martin et al., 1986). Sulfate-free medium was an M9 medium (Maniatis et al., 1982), except that $\mathrm{MgCl}_{2}$ was used in place of $\mathrm{MgSO}_{4}$. Inorganic sulfur sources were added as described by Cherest \& Surdin-Kerjan (1992). IPTG was used at $1 \mathrm{mM}$ or $5 \mathrm{mM}$ for $E$. coli or $P$. aeruginosa cultures, respectively.

The conjugative properties of pRK2013 (Figurski \& Helinski, 1979) were used to transfer recombinant plasmids from $E$. coli to $P$. aeruginosa. Pseudomonas transconjugants were then screened on Pseudomonas isolation agar (PIA; Difco) supplemented with antibiotics at the following concentrations : for E. coli ampicillin (Ap), $50 \mu \mathrm{g} \mathrm{ml}^{-1}$ and streptomycin (Sm), $100 \mu \mathrm{g} \mathrm{ml}^{-1}$; for $P$. aeruginosa carbenicillin (Cb), $300 \mu \mathrm{g} \mathrm{ml}^{-1}$ and streptomycin (Sm) $1 \mathrm{mg} \mathrm{ml}^{-1}$.

DNA methods. DNA fragments used in subcloning were purified by low-melting-point agarose gel electrophoresis. Cleavage with restriction endonucleases, ligation and transformation were done as described in Maniatis et al. (1982). Sequencing on both strands was done as described by Bally $e t a l$. (1992). Various endonuclease restriction fragments encompassing the $1.9 \mathrm{~kb}$ HindIII-SmaI insert were obtained from the plasmid pMM18 (Filloux et al., 1989; see Fig. 2).

Enzymic assays. Cell extracts were prepared by sonication. $O$ Acylhomoserine sulfhydrylase was assayed as described by Wiebers \& Garner (1967). The following concentrations were used: sodium sulfide, $10 \mathrm{mM}$; pyridoxal 5-phosphate (PLP), $0.2 \mathrm{mM}$; $O$-succinylhomoserine (or $O$-acetylhomoserine), $20 \mathrm{mM}$; Tris, $\mathrm{pH} 8,0.1 \mathrm{M}$; final volume $0.1 \mathrm{ml}$. The homocysteine formed was estimated according to the method described by Kredich \& Tomkins (1966). Protein concentrations were estimated by the biuret method.

Chemicals. All reagents, including amino acids, were Sigma grade. O-Acetylhomoserine was a generous gift from $\mathrm{Dr}$ Y. Surdin-Kerjan.

\section{RESULTS}

\section{Growth requirements of mutants}

The growth requirements of strains PAO8 (met-28) and PAO503 (met-9011) were studied and compared to the wild-type PAO1. In both strains (see Table 2), methionine auxotrophy was confirmed, and homocysteine could replace methionine. Growth (slower than normal) was observed on cysteine with PAO503 but not with PAO8 (similar results were obtained on sulfate-free medium). None of the other compounds tested led to growth of the mutants. This can be easily explained in the case of $O$ succinylhomoserine and $O$-acetylhomoserine, as it is usually observed that these acylated compounds are poorly transported into bacteria. The permeation of cystathionine in $P$. aeruginosa is not known.

From these results, the following hypotheses can be made: (i) interconversion between cysteine and methionine is possible in strain PAO503, as already proposed by Gunther et al. (1979) and Schelenz et al. (1986); (ii) strain PAO503 should be blocked in the last steps prior to cysteine biosynthesis; (iii) the met-28 mutation must affect one gene corresponding to $\operatorname{met} A, \operatorname{met} B$ or $\operatorname{met} C$.

\section{Complementation tests}

Heterologous complementation was tested using the $E$. coli met $A$ and met $B$ genes. These genes were cloned downstream of a tac promoter, which is known to be 
Table 1. Bacterial strains and plasmids

\begin{tabular}{|c|c|c|}
\hline Strain/plasmid & Relevant characteristics & Source/reference \\
\hline \multicolumn{3}{|l|}{ Strains } \\
\hline \multicolumn{3}{|l|}{ P. aeruginosa } \\
\hline PAO1 & Prototroph $(c h l-2)$ & B. W. Holloway collection \\
\hline PAO8 & $m e t-28$ ilv-202 str-1 & B. W. Holloway collection \\
\hline PAO503 & met-9011 & B. Wretlind \\
\hline \multicolumn{3}{|l|}{ E. coli } \\
\hline MC4100 & $\operatorname{araD} \Delta \mathrm{lac} U 169 \mathrm{rpsL}$ relA thi & Maniatis et al. (1982) \\
\hline$\beta 180$ & $\operatorname{met} A:: \mathrm{Cm}^{\mathrm{R}}$ & Richaud et al. (1993) \\
\hline WA802 & metB1 lac galK2 galT22 supE44 bsdR2 & Richaud et al. (1993) \\
\hline \multicolumn{3}{|l|}{ Plasmids } \\
\hline $\mathrm{pRK} 2013$ & ColE1, $\mathrm{Tra}^{+} \mathrm{Mob}^{+}, \mathrm{Km}^{\mathrm{R}}$ & $\begin{array}{l}\text { Figurski \& Helinski } \\
(1979)\end{array}$ \\
\hline pMMB67HE & $\begin{array}{l}\text { whr RSF1010 replicon, tac promoter, } \\
\mathrm{Ap}^{\mathrm{R}} / \mathrm{Cb}^{\mathrm{R}}\end{array}$ & Fürste et al. (1986) \\
\hline $\begin{array}{l}\text { pUC9 and } \\
\text { pUC13 }\end{array}$ & ColE1, lacI', $\Phi 80$ dlac $Z, \mathrm{Ap}^{\mathrm{R}}$ & $\begin{array}{l}\text { Yanisch-Perron et al. } \\
(1985)\end{array}$ \\
\hline pMA61 & E. coli met $A$ cloned in pUC13 & Richaud et al. (1993) \\
\hline pMB41 & E. coli metB cloned in pUC9 & Richaud et al. (1993) \\
\hline PMMA1 & $\begin{array}{l}2 \cdot 1 \mathrm{~kb} \text { EcoRI-HindIII fragment from } \\
\text { pMA61 containing } E \text {. coli met } A \text { cloned } \\
\text { in pMMB67HE }\end{array}$ & This work \\
\hline pMMB17 & $\begin{array}{l}1.3 \mathrm{~kb} \text { Eco RI-HindIII fragment from } \\
\text { pMB41 containing E. coli metB cloned } \\
\text { in pMMB } 67 \mathrm{HE}\end{array}$ & This work \\
\hline pGSS8 & IncQ, $\mathrm{Tc}^{\mathrm{R}}, \mathrm{Sm}^{\mathrm{R}}$ & Sharpe (1984) \\
\hline pMM18 & $\begin{array}{l}\text { pGSS } 8 \text { containing a } 10 \mathrm{~kb} \text { PAO1 DNA } \\
\text { fragment }\end{array}$ & Filloux et al. (1989) \\
\hline pMP5 & $\begin{array}{l}1.9 \mathrm{~kb} \text { HindlII }-S m a I \text { fragment from } \\
\text { pMM18 cloned in pMMB67HE }\end{array}$ & This work \\
\hline
\end{tabular}

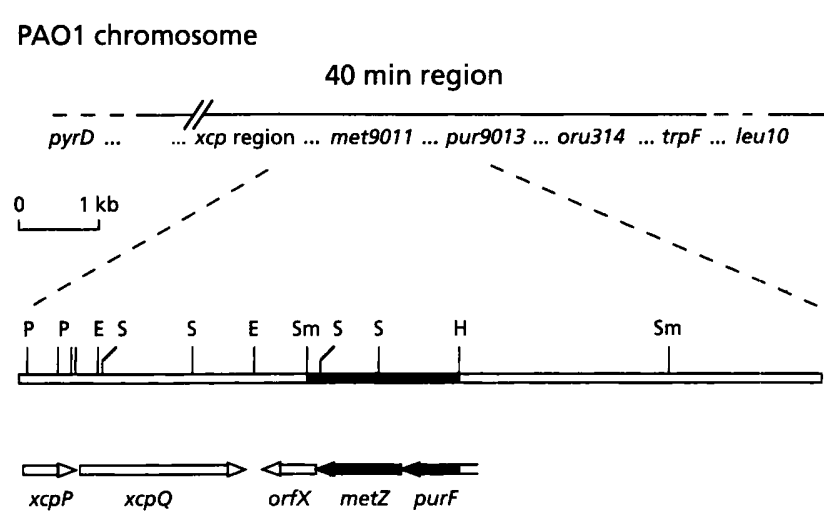

Fig. 2. Genetic organization and restriction endonuclease map of the met $Z$ region. The most probable order of the genetic markers in the 40 min region is based on the genetic map of $P$. aeruginosa (Holloway \& Zhang, 1990) and on previous data (Akrim et al., 1993). The DNA fragment originated from pMM18 (Filloux et al., 1989). The $1.9 \mathrm{~kb}$ sequenced fragment containing metZ is shown in filled bars. Restriction sites are indicated as follows: E, EcoRI; H, HindIII; P, Pstl; S, Sall; Sm, Smal. operative in Pseudomonas (Fürste et al., 1986), on plasmid pMMB67HE (see Table 1) leading to pMMA1 and pMMB17, respectively; these hybrid plasmids were transferred by triparental mating in the Pseudomonas mutant strains. Results are given in Table 3.

The defect of strain PAO8 is complemented by expression of the $E$. coli met $A$ gene. This indicates that the met-28 mutation affects the corresponding Pseudomonas gene and that $O$-succinylhomoserine should be the normal methionine precursor in Pseudomonas as in E. coli.

The defect in strain PAO503 is complemented by the expression of the $E$. coli met $B$ gene. As this enzyme normally uses cysteine and $\mathrm{O}$-acylhomoserine for cystathionine synthesis, this result should indicate that cysteine must be synthesized in the mutant (contradicting our preceding hypothesis). On the other hand, the possibility that the met-9011 mutation could affect a cystathioninesynthase-encoding gene is in contradiction with the fact that the mutant can grow in the presence of cysteine alone. As the corresponding wild-type DNA fragment had been isolated by Filloux et al. (1989), a $1.9 \mathrm{~kb}$ HindIII-SmaI DNA fragment containing the gene was subcloned on pMMB67HE downstream of a tac promoter leading to plasmid pMP5. When pMP5 was introduced into PAO503 


\section{Table 2. Growth requirements}

Inocula were prepared from bacteria grown on minimal medium plus methionine. Growth was estimated after $24 \mathrm{~h} .++$, Normal growth; + , growth slower than normal; $-/+$, poor growth; - , lack of detectable growth. Abbreviations: $\mathrm{OSH}, \mathrm{O}-$ succinylhomoserine; OAH, O-acetylhomoserine; Cyst, cystathionine; Hcys, homocysteine.

\begin{tabular}{|clccc|}
\hline & Supplement & \multicolumn{3}{c|}{ Strain } \\
\cline { 3 - 5 } & & PAO1 & PAO503 & PAO8 \\
\hline Minimal & None & ++ & - & - \\
medium & OSH or OAH & ++ & - & - \\
& Cyst & ++ & - & - \\
& Hcys & ++ & ++ & ++ \\
& Cys & ++ & + & - \\
Minimal & None & ++ & ++ & ++ \\
SF* & Sulfate, sulfite & ++ & - & - \\
& or sulfide & & & - \\
& Cyst & ++ & - & - \\
& Hcys & ++ & ++ & ++ \\
& Cys & ++ & + & - \\
& Met & ++ & ++ & ++ \\
\hline
\end{tabular}

* Sulfate-free medium.

and WA802 (E. coli metB), complementation was obtained with the former but not with the $E$. coli mutant strain (negative results were also obtained with other $E$. coli methionine auxotrophs; not shown). This negative result led us to think that the $E$. coli pathway is not operative in Pseudomonas and that this species follows the yeast pathway, using $\mathrm{O}$-acylsulfhydrylase activity.

Measurements of such an activity were thus performed in the different strains. Results are given in Table 4. Whereas
Table 4. O-Succinylhomoserine sulfhydrylase activity

O-Succinylhomoserine (OSH) sulfhydrylase specific activities (nmol homocysteine produced $\mathrm{min}^{-1} \mathrm{mg}^{-1}$ ) were determined on cell-free extracts as described in Methods. Bacteria were grown in minimal medium in the presence of IPTG. Plasmids are described in Table 1. Values are the means of at least three independent experiments. ND, Not detectable in our assay conditions.

\begin{tabular}{|lllc|}
\hline Strain & \multicolumn{2}{c|}{ Plasmid } & $\begin{array}{c}\text { OSH- } \\
\text { sulfhydrylase } \\
\text { specific }\end{array}$ \\
\cline { 2 - 4 } activity
\end{tabular}

no activity could be detected in $E$. coli as expected, $O$ succinylhomoserine is actively converted into homocysteine in $P$. aeruginosa wild-type cell-free extracts; it must be pointed out that $O$-acetylhomoserine was not a substrate, confirming the identity of the first step between $E$. coli and Pseudomonas. No activity could be detected in PAO503, whereas it was restored in this mutant harbouring the multicopy plasmid pMP5. The observed level is, in our experimental growth conditions in the presence of IPTG, similar to the one of PAO1 wild-type strain. This plasmid was also expressed in the $E$. coli met $B$ mutant WA802

\section{Table 3. Complementation tests}

Bacterial growth was performed in the presence of IPTG and estimated as described in Table 2. Plasmids are described in Table 1. pMMB67HE is used as a control, pMMA1 carries the E. coli met $A$ gene, pMMB17 carries the E. coli metB gene and pMP5 carries the $P$. aeruginosa met $Z$ gene. Symbols are the same as in Table 2.

\begin{tabular}{|c|c|c|c|c|c|}
\hline \multirow[t]{2}{*}{ Strain } & \multirow[t]{2}{*}{ Genotype } & \multicolumn{4}{|c|}{ Plasmid used for complementation: } \\
\hline & & $\begin{array}{l}\text { PMMB67HE } \\
\text { (vector) }\end{array}$ & $\begin{array}{c}\text { pMMA1 } \\
(\operatorname{met} A)\end{array}$ & $\begin{array}{c}\text { pMMB17 } \\
(\text { metB) }\end{array}$ & $\begin{array}{l}\text { pMP5 } \\
\text { (metZ) }\end{array}$ \\
\hline \multicolumn{6}{|l|}{ E. coli } \\
\hline MC4100 & Wild-type & ++ & ++ & ++ & ++ \\
\hline$\beta 180$ & $\operatorname{met} A$ & - & ++ & - & - \\
\hline WA802 & $m e t B$ & - & - & ++ & - \\
\hline \multicolumn{6}{|c|}{$P$. aeruginosa } \\
\hline PAO1 & Wild-type & ++ & ++ & ++ & ++ \\
\hline PAO8 & $m e t-28$ & - & ++ & - & - \\
\hline PAO503 & met-9011 & - & - & + & ++ \\
\hline
\end{tabular}


$>$ PurF

1 CCTCCGCGAGCGTCCGACCACGACATCGACGTGGTCATCCCGATCCCGGACACCAGCCGCACCGCGCGGCTGGAACTGGCCAACCGGCTCGGCGTGAAGT

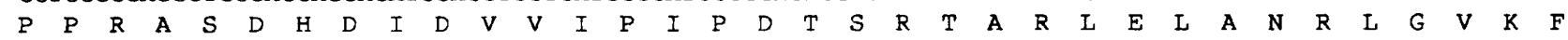
101 TCCGCGAGGGCTTCGTCAAGAACCGCTACATCGGCCGCACCTTCATCATGCCCGGCCAGGCGGCGCGGAAGAAATCCGTGCGGCAGAAGCTCAACGCCAT $\begin{array}{llllllllllllllllllllllllllllllllll}R & E & G & F & V & K & N & R & Y & I & G & R & T & F & I & M & P & G & Q & A & A & R & K & K & S & V & R & Q & K & I & N & A & I\end{array}$

201 CGAGCTGGAGTTCCGCGGCAAGAACGTGATGCTGGTGGATGACTCCATCGTCCGCGGCACCACCTGCAAGCAGATCATCCAGATGGCCCGCGAGGCCGGG $\begin{array}{lllllllllllllllllllllllllllllllllll}E & L & E & F & R & G & K & N & V & M & L & V & D & D & S & I & V & R & G & T & T & C & K & Q & I & I & Q & M & A & R & E & A & G\end{array}$

301 GCGAAGAACGTCTACTTCTGCTCCGCCGCGCCGGCCGTGCGCTACCCCAACGTCTACGGCATCGACATGCCGAGTGCGCACGAGCTGATCGCGCACAATC

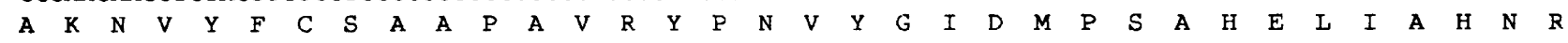
401 GCAGCACCGAGGACGTCAGCAAGCTGATCGGCGCCGACTGGCTGGTCTACCAGGACCTGCCCGACCTGATCGACGCGGTCGGCGGCGGCAAGATCAAGAT $\begin{array}{llllllllllllllllllllllllllllllllll}S & T & E & D & V & S & K & I & I & G & A & D & W & L & V & Y & Q & D & L & P & D & L & I & D & A & V & G & G & G & K & I & K & I\end{array}$

501 CGATCACTTCGACTGCGCCGTGTTCGACGGCGAGTACGTGACCGGCGACGTCAACGAGGCCTACCTGAACCGGATCGAACAGGCGCGCAACGATGCGACC

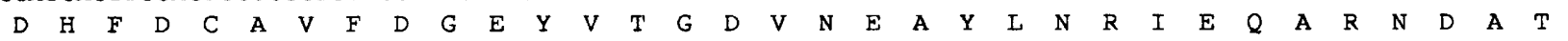
601 AAGGCCAAGAGCCAGGCGTCAGCGCGATCATCGATCTGTACAACGACTGACAAAGGGAGAGCGCATGACTCAGGACTGGGATGCCGGGCGTCTCGAC $\begin{array}{lllllllllllllllllllllllllllll}K & A & K & S & Q & A & V & S & A & I & I & D & L & Y & N & D & \star & \text { M } & \text { T } & Q & D & \text { W } & D & A & G & R & L & D\end{array}$

701 AGCGACCTGGAAGGCGCGGCCTTCGACACCCTGGCGGTTCGCGCCGGGCAACGGCGGACGCCGGAGGGCGAGCACGGCGAGGCGCTGTTCACCACTTCCA

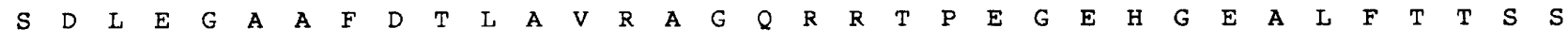
801 GCTACGTCTTCCGCACCGCCGCCGACGCGGCCGCGCGGTTCGCCGGCGAÄTGCCGGCCAACGTCTATTCGCGCTACACCAACCCCACGGTACGCACCTT

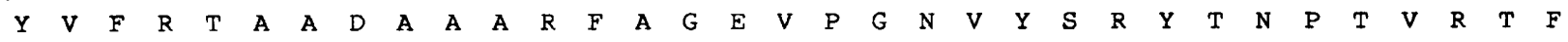
901 CGAGGAGCGCATCGCCGCCCTCGAAGGAGCCGAGCAGGCGGTGGCCACGGCGTCGGGCATGTCGGCGATCCTCGCCCTGGTGATGAGCCTGTGCAGCTCC $\begin{array}{lllllllllllllllllllllllllllllllllll}E & E & R & I & A & A & I & E & G & A & E & Q & A & V & A & T & A & S & G & M & S & A & I & L & A & L & V & M & S & L & C & S & S\end{array}$

1001 GGCGACCACGTGCTGGTCTCGCGCAGCGTGTTCGGCTCGACCATCAGCCTGTTCGACAAGTACTTCAAGCGCTTCGGTATCCAGGTCGACTATCCGCCGT $\begin{array}{lllllllllllllllllllllllllllllllllll}G & D & H & V & L & V & S & R & S & V & F & G & S & T & I & S & L & F & D & K & Y & F & K & R & F & G & I & Q & V & D & Y & P & P & L\end{array}$ 1101 TGAGCGATCTCGCGGCCTGGGAGGCGGCGTGCAAGCCGAATACCAAGCTGTTCTTCGTCGAGTCGCCATCCAACCCGCTGGCCGAGCTGGTGGATATCGC $\begin{array}{llllllllllllllllllllllllllllllllllll}\text { S } & D & \text { L } & \text { A } & \text { A } & \text { W } & \text { E } & \text { A } & \text { A } & C & \text { C } & \text { K } & \text { P } & \text { N } & \text { T } & \text { K } & \text { L } & \text { F } & \text { F } & \text { V } & \text { E } & \text { S } & \text { P } & \text { S } & \text { N } & \text { P } & \text { L } & \text { A } & \text { E } & \text { L } & \text { V } & \text { D } & \text { I } & \text { A }\end{array}$ 1201 CGCGCTGGCCGAGATCGCCCACGCCAAGGGTGCGCTGCTGGCGGTGGACAACTGCTTCTGCACGCCGGCCCTGCAACAGCCGCTGAAGCTCGGTGCGGAC $\begin{array}{llllllllllllllllllllllllllllllllll}\text { A } & \text { L } & \text { A } & \text { E } & \text { I } & \text { A } & \text { H } & \text { A } & \text { K } & G & \text { A } & \text { L } & \text { L } & \text { A } & \text { V } & \text { D } & \text { N } & \text { C } & \text { F } & \text { C } & \text { T } & \text { P } & \text { A } & \text { L } & Q & Q & \text { P } & \text { L } & \text { K } & \text { L } & G & \text { A } & \text { D }\end{array}$ 1301 GTGGTGATCCACTCCGCGACCAAGTACATCGACGGCCAGGGCCGGGGCATGGGCGGGGTGGTCGCCGGTCGCGGCGAGCAGATGAAGGAAGTGGTCGGCT $\begin{array}{lllllllllllllllllllllllllllllllllll}V & V & I & H & S & A & T & K & Y & I & D & G & Q & G & R & G & M & G & G & V & V & A & G & R & G & E & Q & M & K & E & V & V & G & F\end{array}$ 1401 TCCTCCGCACCGCCGGACCGACCCTCAGCCCGTTCAACGCCTGGCTGTTCCTCAAGGGCCTGGAAACCCTGCGTATCCGCATGCAGGCGCACAGCGCCAG $\begin{array}{lllllllllllllllllllllllllllllllllll}L & R & T & A & G & P & T & L & S & P & F & N & A & W & L & F & L & K & G & L & E & T & L & R & I & R & M & Q & A & H & S & A & S\end{array}$ 1501 TGCCCTGGCCCTGGCCGAATGGCTGGAGCGCCAGCCGGGCATCGAGCGGGTCTACTACGCGGGCCTGCCGAGCCATCCTCAGCATGAGTTGGCCCGGCGC $\begin{array}{llllllllllllllllllllllllllllllllll}\text { A } & L & A & L & A & E & \text { W } & \text { L } & E & R & Q & P & G & I & E & R & V & Y & Y & A & G & L & P & S & H & P & Q & H & E & L & A & R & R\end{array}$ 1601 CAGCAGAGCGGCTTCGGCGCGGTCGTCAGCTTCGACGTGAAGGGCGGGCGCGATGCCGCCTTGGCGCTTCATCGACGCTACCCGGATGGTCTCGATCACCA $\begin{array}{lllllllllllllllllllllllllllllllllll}Q & Q & S & G & F & G & A & V & V & S & F & D & V & K & G & G & R & D & A & A & W & R & F & I & D & A & T & R & M & V & S & I & T & T\end{array}$ 1701 CCAACCTGGGCGACACCAAGACCACCATCGCCCACCCGGCGACCACCTCCCACGGTCGACTGTCCCCCGAGGACCGCGCGCGCGCCGGGATCGGCGACAG

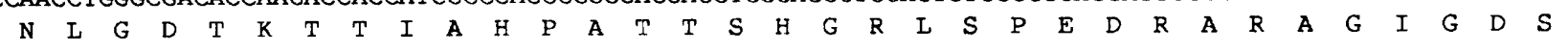
1801 CCTGATCCGGGTCGCGGTCGGCCTGGAAGACCTCGACGACCTCAAGGCCGACATGGCTCGGGGGCTGGCCGCGCTGTGATCGAACCCAACCTGCGAGGCA $\begin{array}{llllllllllllllllllllllllllll}L & I & R & V & A & V & G & L & E & D & L & D & D & L & K & A & D & M & A & R & G & L & A & A & L & *\end{array}$

1901 ACGGCAAGGTCGCCCTGGTCACCGGGGCGGCCCGGG

Fig. 3. Nucleotide sequence of the $1.9 \mathrm{~kb}$ fragment encoding Metz.

(even though a negative complementation test for restoring growth was obtained).

These results led us to conclude that the DNA fragment cloned encodes a protein with $O$-succinylhomoserine sulfhydrylase activity.

\section{Sequence of the sulfhydrylase gene}

The nucleotide sequence of the $1.9 \mathrm{~kb}$ insert of pMP5 was determined on both strands as described in Methods. It is given in Fig. 3. A 1209 bp ORF (extending from position 668 to 1876 ) was evidenced. Its $G+C$ content and a strong 
MetB

Metz

Met25

$M T-$ - RKEA-

TIAVRSGLNDDEQYG-

CVVPPIHLSSTYNFTGPNEP---

1 MTQDWDAGRLDSDLEGAAFDTLAVRAGQRRTPE-G--EHGEALFTTSSYVFRTAADAAAR

Met 25

1 $\star$ -FDTVQLHAGQENPGDNAHRSRAVPIYATTSYVFENSKHGSQL

MetB

Metz

Met 25

42 ----RAHDYSRRGNPTRDVVQRALAELEGGAGAVLTNTGMSAIHLVTTVFLKP GDWAVA

58 FAGEVPGNVYSRYTNPTVRTFEERIAALEGA EQAVATASGMSAILALVMSLCSS SDHVLV

49 FGLEVPGYVYSRFQNPTSNVIEERIAALEGGAAALAVSSGQAAQTLAIQGLAHT GDNIVS

MetB 97 PHDCYGGSYRLPDSLAKRGCYRVLFVDQGDEQALRAALAEKPKLVAVESPSNPLARVVDT

Metz 118 SRSVFGSTISLFDKYFKRFGIQVDYPPLSDLAAWEAACKPNFKLFFVESPSNPLAEIUDT

Met25 107 TSYLYGGTYNQFKISFKRFGIEARFVEGDNPEEFEKVFDER EKAVYLETIGNPKYNVPDF

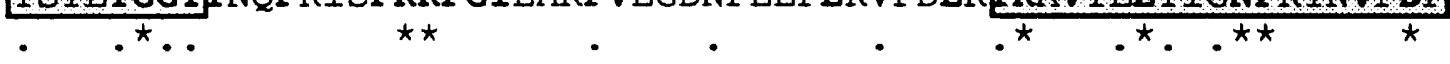

MetB 157 AKICHLAREVGAYSVVDNTFLSPA-LQNPLALGADLVLHSCIKYMNGHSDVVAGVVIAKD Metz 178 AALAEIAHAKGAI LAVDNCF CTPA-LQdPLKLGADVVIHSATKYIDGQGRGMGGVVAGRG Met25 167 EKIVAIAHKHGI VVVVDNTF GAGGYFCDPIKYGADIVTHSATKWIGGHGTTIGGIIVDSG

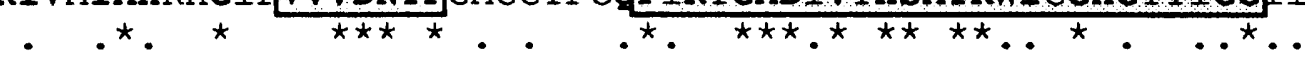

MetB 216 PDVVTELAW-Metz 237 EQMKEVVGF-Met25 227 KFPWKDYPEKFPQFSQPAEGYHGTIYNEAYGNLAYIVHVRTELLRDLGPIMNPFASFLLL

MetB 243 RGLRTIVPRMELAQRNAQAIVKYLQTQPIVKKLYHPSLPENQGHI IAAR-QQKGFGAMLS Metz 263 KGLETLRIRMQAHSASALALAEWLERQPGIERVYYAGLPSHPQHR LARR-QQSGFGAVVS Met25 287 QGVETHSLRAERHGENALKLAKWLEQSPYVSWVSYPGLASHSHHINAKKYLSNGFGGVLS

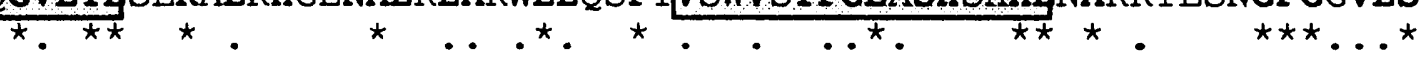

MetB 302 FELDGDEQTLR-------RFLGGLSLFTLAESLGGVESLISHAATMTHAGMAPEARA Metz 322 FDVKGGRDAAW--------RFIDATRMVSITTNLGDTKTTIAHPATTSHGRLSPEDRA Met25 347 FGVKDLPNADKETDPFKLSGAQVVDNLKLASNLANVGDAKTLVIAPYFTTHKQLNDKEKL $\star \quad . \quad$.

MetB 352 AAGISETLIRISTGIEDGEDLIADTENGFRAA---NKG

Metz 372 RAGIGDSLIRVAVGLEDLDDLKADMARGLAAL-----

Met25 407 ASGVTKDLIRVSVGIEFIDDIIADFQQSFETVFAGQKP . *.. ${ }^{\star}{ }^{\star} \cdot{ }^{\star} \cdot{ }^{\star} \cdot{ }^{\star} \cdot{ }^{\star}{ }^{\star}$. .

Fig. 4. Sequence alignment of the $E$. coli MetB, the $S$. cerevisiae Met25 and the $P$. aeruginosa MetZ proteins. Boxed sequences of similarities are taken from Cherest et al. (1993). Asterisks indicate identical residues between the three sequences and dots indicate homologous residues. Residues shared by at least two proteins are in bold letters.

bias in the third position codon usage are typical of chromosomally encoded Pseudomonas genes (West \& Iglewski, 1988). The corresponding protein (403 amino acids long; $\left.M_{\mathrm{r}} 43186\right)$ is tentatively named MetZ.

Computer analysis indicated strong similarities with the E. coli MetB cystathionine $\gamma$-synthase and with the yeast $O$-acetylhomoserine sulfhydrylase (product of the MET25 gene) (Fig. 4). These similarities (36.8\% and $36.7 \%$ identity, respectively) are observed all along the sequences. The Met $Z$ protein belongs to one of the two families of transsulfuration enzymes recently defined by Cherest et al. (1993) including the rat and yeast cystathionine $\gamma$-lyases, the yeast homocysteine synthase, and both the cystathionine $\gamma$-synthase and cystathionine $\beta$ lyase from E. coli. For sake of clarity, Fig. 4 gives sequence alignments of only three sequences, and the conserved blocks observed by Cherest et al. (1993) are indicated; it can be seen that these blocks are also found in our sequence. Comparison with Met $Z$ allows some additional observations: even though the calculated percentage of identical residues is globally similar when 
comparing Met $Z$ to Met 25 or MetB entire sequences, Pseudomonas Met $Z$ and yeast Met 25 proteins display much longer conserved regions than E. coli MetB in their Nterminal part (till residue 90). The main difference between these two proteins is the additional presence of a stretch of about 30 amino acids in the yeast enzyme when compared to the two others. All these enzymes use PLP as a cofactor. In E. coli MetB Parsot et al. (1987) have shown that the Lys198 residue is covalently bound to PLP and Cherest et al. (1993) have already noted the strong conservation of this region; it is likely that Lys219 of MetZ must play a similar role.

The C-terminal part of an incomplete ORF (216 codons; position 1-648 in Fig. 3) was observed upstream of met $Z$ which also possesses the characteristics of a Pseudomonas expressed sequence. Screening of the data banks indicated a very strong similarity $(59 \cdot 2 \%$ and $52.8 \%$ identity, respectively) with the C-terminal parts of the E. coli PurF (Tso et al., 1982) and the S. cerevisiae Ade4 (Mäntsälä \& Zalkin, 1984) glutamine phosphoribosylpyrophosphate amidotransferases. We thus propose this ORF to be called PurF; this is in agreement with the fact that a mutation leading to purine auxotrophy (pur-9013) has been localized in this region on the Pseudomonas chromosome (O'Hoy \& Krishnapillai, 1987). The last codon of PurF is only 16 bp upstream from the ATG of MetZ.

\section{DISCUSSION}

In $P$. aeruginosa three loci have been described with mutations leading to a $\mathrm{Met}^{-}$phenotype: one is located at $20 \mathrm{~min}$ on the chromosome; a second at $40 \mathrm{~min}$; the third at $31 \mathrm{~min}$. In fact it has been shown by Clepet et al. (1992) that this last locus encodes homoserine dehydrogenase, the enzyme that synthesizes homoserine, the precursor of both threonine and methionine (growth of mutants in this gene is obtained in the presence of homoserine alone or threonine plus methionine).

We have studied mutations mapping at the two other loci by different approaches: determination of the growth requirements of the corresponding mutants, possibility of heterologous complementation, measurements of sulfhydrylase enzymic activity, and the sequencing of one locus.

At 20 min several $\mathrm{Met}^{-}$mutants were mapped (met-28; met-60; met-66; met-8003). They appear to be all linked, with the possible exception of met-8003, but we could not obtain this mutant from other laboratories. The met-28 mutation was chosen as a representative of this class. It is complemented by the expression of the E. coli met $A$ gene, in agreement with growth in the presence of homocysteine. Thus this region encodes an homoserine $O$ succinyltransferase activity, the product of the Pseudomonas met $A$ gene. The fact that succinyl homoserine is the true acyl intermediate is strengthened by our data indicating that this ester is the only substrate used in the following enzymic step.

It is not known if other methionine genes are located in this region. However as the gene organization in the two other loci is known (see below and Clepet $e$ t al., 1992), and if we take account for the fact that mutants affecting all possible steps have been already isolated, one may postulate that the gene(s) encoding methionine synthase, the last step in the pathway, will also map in this $20 \mathrm{~min}$ region.

Our results show that the met-9011 mutation (located at $40 \mathrm{~min}$ ) affects a gene encoding $O$-succinylhomoserine sulfhydrylase activity; we propose to call this gene $m e t Z$. This is indicated by: (i) the loss of such an activity in the mutant strain, whereas it exists in the wild-type parental strain; (ii) the fact that a $1.9 \mathrm{~kb}$ DNA fragment carrying this region complements this mutation and expresses the sulfhydrylase activity both in Pseudomonas and in E. coli. Moreover conserved regions are observed in the $\mathrm{N}$ terminal part of Met $Z$ and the corresponding yeast enzyme that could reflect functional similarities.

The sequence of the fragment was entirely determined and no other entire ORF was present. Moreover the sequence of 14 contiguous $\mathrm{kb}$ is actually known in this region, and no genes were found to be homologous to any methionine genes: downstream is an orf $X$, encoding a putative protein similar to FixR of B. japonicum (Akrim et al., 1993), followed by several $x c p$ loci involved in protein secretion (Bally et al., 1992); upstream is a putative PurFencoding sequence (this paper; see Fig. 2). Thus no other gene involved in methionine biosynthesis is located in this region. This eliminates the possibility that the met-9011 mutation will have a polar effect, leading to pleiotropic requirements for intermediates of methionine biosynthesis and to difficulties in the interpretation of complementation tests.

Thus Pseudomonas differs from enteric bacteria by the existence of a direct sulfhydrylation pathway, as in $B$. flavum and $S$. cerevisiae, except that $O$-succinylhomoserine is used as the substrate instead of $O$-acetylhomoserine, which is used by the other two species. To our knowledge, $P$. aeruginosa is the only organism so far described using $O$ succinylhomoserine as substrate for direct sulfhydrylation.

Another important point is indicated by the fact that the mutant impaired in $O$-succinylhomoserine sulfhydrylase activity (but not the mutant lacking $O$-acylhomoserine synthesis) can fulfil its auxotrophy by cysteine. Though the direct sulfhydrylation has to be the major route (as indicated by the slow growth of the mutant on cysteine), the $\mathrm{C} 3$ to $\mathrm{C} 4$ transsulfuration pathway must exist in parallel. This could explain the apparently conflicting result we obtained by complementing the mutation affecting the sulfhydrylase activity by overexpression of the E. coli metB gene; such an increase in cystathionine $\gamma$ synthase activity would make the transsulfuration pathway more effective for synthesizing homocysteine from cysteine; in this case cysteine would be synthesized from serine in Pseudomonas as in E. coli. However, due to the overall similarity of the phenotypes we favour the hypothesis that Pseudomonas follows the global pathway established for $S$. cerevisiae by Cherest \& Surdin-Kerjan (1992), in which serine sulfhydrylase is inoperative and 
cysteine is synthesized only by the reverse C4 to C3 transsulfuration pathway. In such a situation, complementation of the Pseudomonas met $Z$ mutant by the E. coli met $B$ gene could be explained as proposed by Richaud $e t$ al. (1993). These authors have recently observed that met $B$ overexpression in E. coli allows homocysteine synthesis in a strain with a metC disrupted gene. They suggest that a bypass of cystathionine through the condensation of a sulfur moiety other than cysteine with $\mathrm{O}$-succinylhomoserine could be challenged by the MetB enzyme, as already suggested by the work of Flavin \& Slaughter (1967), who observed the existence of a 'parasite' sulfhydrylase activity in vitro for this protein, and of Simon \& Hong (1983), who isolated E. coli metQ mutants displaying a phenotype similar to the one obtained by Richaud et al. (1993). As the Pseudomonas MetZ protein is inoperative for complementing E. coli metB (and met $C$ ) mutants, we have to suppose that the sulfur donor is not the same, or has quite different affinities, for the MetZ and MetB proteins. Isolation of mutants similar to those isolated in S. cerevisiae would be necessary to prove that Pseudomonas strictly follows the yeast pathway as described in Fig. 1(b).

One might note that such a relationship between yeast, Brevibacterium and Pseudomonas has already been noted when comparing identical enzymes from different organisms: a stronger similarity was observed between Pseudomonas and yeast proteins and Pseudomonas and Brevibacterium proteins than between Pseudomonas and E. coli (Cami et al., 1993).

Finally, one may wonder why cystathionine cannot replace cysteine for the growth of strains PAO503. Two phenomena, acting together, may account for this. First, the uptake of cystathionine could be poorly achieved in Pseudomonas. Cystathionine auxotrophs have been described in Pseudomonas (Calhoun \& Feary, 1969); however, the authors indicated that growth was very poor in the presence of cystathionine and that the chemical product used in their tests was not chromatographically pure. Such a poor permeation in this species compared to E. coli has already been proposed in the case of diaminopimelate (Martin et al., 1986). Second, the reaction synthesizing homocysteine, then methionine, from cystathionine could be poorly active in Pseudomonas, as it seems to be the case in yeast. In both such conditions, cystathionine would not be at a concentration high enough in the cell to allow both methionine and cysteine syntheses. These hypotheses would explain the results we obtained when growing cells in sulfate-free medium (Table 2). In such a medium, a residual sulfate concentration, as revealed by poor growth without addition, would allow methionine synthesis, with a sparing effect of cystathionine used as a precursor of cysteine; this would not be possible in the mutant strain PAO503. As similar phenotypes are observed in yeast (Pigg et al., 1962; H. Cherest, personal communication), this reinforces our hypothesis that Pseudomonas and yeast follow the same global pathway.

The simultaneous presence of the two transsulfuration pathways in Pseudomonas raises the question of their physiological meaning. In this respect, it would be interesting to know if differential expression of these pathways could be achieved according to regulatory mechanisms depending on specific growth conditions.

\section{ACKNOWLEDGEMENTS}

We particularly wish to thank Dr Y. Surdin-Kerjan and D. Thomas for helpful discussions and comments on the manuscript, C. Richaud for gift of strains and A. CornishBowden for critical reading. A. Lazdunski is acknowledged for her constant support. This work was supported by grants from the Centre National de la Recherche Scientifique and the Université Aix-Marseille II.

\section{REFERENCES}

Akrim, M., Bally, M., Ball, G., Tommassen, J., Teerink, H., Filloux, A. \& Lazdunski, A. (1993). Xcp mediated protein secretion in Pseudomonas aeruginosa: identification of two additional genes and evidence for regulation of $x c p$ gene expression. Mol Microbiol 10, 431-443.

Bally, M., Filloux, A., Akrim, M., Ball, G., Lazdunski, A. \& Tommassen, J. (1992). Protein secretion in Pseudomonas aeruginosa: characterization of seven $x c p$ genes and processing of secretory apparatus components by prepilin peptidase. Mol Microbiol 6, 1121-1131.

Belfaiza, J., Parsot, C., Martel, A., Bouthier de la Tour, C., Margarita, D., Cohen, G. N. \& Saint Girons, I. (1986). Evolution in biosynthetic pathways: two enzymes catalyzing consecutive steps in methionine biosynthesis originate from a common ancestor and share a common regulatory region. Proc Natl Acad Sci US A 83, 867-871.

Calhoun, D. H. \& Feary, T. W. (1969). Transductional analysis of Pseudomonas aeruginosa methionineless auxotrophs. J Bacteriol 97, 210-216.

Cami, B., Clepet, C. \& Patte, J. C. (1993). Evolutionary comparisons of three enzymes of the threonine biosynthetic pathway among several microbial species. Biochimie 75, 487-495.

Cherest, H. \& Surdin-Kerjan, Y. (1992). Genetic analysis of a new mutation conferring cysteine auxotrophy in Saccharomyces cerevisiae: updating of the sulfur metabolism pathway. Genetics 130, 51-58.

Cherest, H., Thomas, D. \& Surdin-Kerjan, Y. (1993). Cysteine biosynthesis in Saccharomyces cerevisiae occurs through the transsulfuration pathway which has been built up by enzyme recruitment. J Bacteriol 175, 5366-5374.

Chu, J., Shoeman, R., Hart, J., Coleman, T., Mazaitis, A., Kelher, N., Brot, N. \& Weissbach, H. (1985). Cloning and expression of the metE gene in Escherichia coli. Arch Biochem Biopbys 239, 467-474.

Clepet, C., Borne, F., Krishnapillai, V., Baird, C., Patte, J. C. \& Cami, B. (1992). Isolation, organization and expression of the Pseudomonas aeruginosa threonine genes. Mol Microbiol 6, 3109-3119.

Duchange, N., Zakin, M. M., Ferrara, P., Saint Girons, I., Park, I., Tran, S. V., Py, M. C. \& Cohen, G. N. (1983). Structure of the metJBLF cluster in E. coli K12. Sequence of the metB structural gene and of the $5^{\prime}$ and $3^{\prime}$ flanking regions of the metBL operon. J Biol Chem 258, 14868-14871.

Figurski, D. H. \& Helinski, D. R. (1979). Replication of an origin containing derivative of plasmid RK2 dependent on a plasmid function provided in trans. Proc Natl Acad Sci US A 76, 1648-1652.

Filloux, A., Bally, M., Murgier, M., Wretlind, B. \& Lazdunski, A. (1989). Cloning of $x c p$ genes located at the $55 \mathrm{~min}$ region of the chromosome and involved in protein secretion in Pseudomonas aeruginosa. Mol Microbiol 3, 261-265. 
Flavin, M. \& Slaughter, C. (1967). Enzymatic synthesis of homocysteine or methionine directly from O-succinylhomoserine. Biochim Biophys Acta 132, 400-405.

Fürste, J. P., Pansegrau, W., Franck, R., Blocker, H., Scholz, P., Bagdasarian, M. \& Lanka, E. (1986). Molecular cloning of the plasmid RP4 primase region in a multi-host-range tac $P$ expression vector. Gene 48, 119-131.

Greene, R. C., Williams, R. D., Kung, H. F., Spears, C. \& Weissbach, H. (1973). Effect of methionine and vitamin B12 on the activities of methionine biosynthetic enzymes in metJ mutants of Eschericbia coli K12. Arch Biochem Biophys 158, 249-256.

Gunther, E., Petruschka, L. \& Herrman, H. (1979). Reverse transsulfuration pathway in Pseudomonas aeruginosa. $Z$ Allg Mikrobiol 19, 439-442.

Holloway, B. W. \& Zhang, C. (1990). Pseudomonas aeruginosa PAO. In Genetic Maps, pp. 271-278. Edited by S. J. O'Brien. Cold Spring Harbor, NY: Cold Spring Harbor Laboratory Press.

Kerjan, P., Cherest, H. \& Surdin-Kerjan, Y. (1986). Nucleotide sequence of the Saccharomyces cerevisiae MET25 gene. Nucleic Acids Res 14, 7861-7871.

Kredich, N. H. \& Tomkins, G. M. (1966). The enzyme synthesis of Lcysteine in Eschericbia coli and Salmonella typhimurium. J Biol Chem 241, 4955-4965.

Langin, T., Faugeron, G., Goyon, C., Nicolas, A. \& Rossignol, J. L. (1986). The MET2 gene of Saccharomyces cerevisiae: molecular cloning and nucleotide sequence. Gene 49, 283-293.

Macnitol, P. K., Datko, A. H., Giovanelli, J. \& Madd, S. H. (1981). Homocysteine biosynthesis in green plants: physiological importance of the transsulfuration pathway in Lemma paucicostata. Plant Physiol 68, 619-625.

Maniatis, T., Fritsch, E. F. \& Sambrook, J. (1982). Molecular Cloning: a Laboratory Manual. Cold Spring Harbor, NY: Cold Spring Harbor Laboratory Press.

Măntsălă, P. \& Zalkin, H. (1984). Glutamine nucleotide sequence of Saccharomyces cerevisiae ADE4 encoding phosphoribosylpyrophosphate amidotransferase. J Biol Chem 259, 8478-8484.

Martin, C., Cami, B., Borne, F., Jeeves, D. J., Haas, D. \& Patte, J. C. (1986). Heterologous expression and regulation of the lys $A$. genes of Pseudomonas aeruginosa and Escherichia coli. Mol \& Gen Genet 203, 430-434.

Michaeli, S. \& Ron, E. Z. (1981). Construction and physical mapping of plasmids containing the met $A$ gene of Escherichia coli K12. Mol \& Gen Genet 182, 349-354.
O'Hoy, K. \& Krishnapillai, V. (1987). Recalibration of the Pseudomonas aeruginosa strain PAO chromosome map in time units using high frequency of recombination donors. Genetics 115, 611-618.

Ozaki, H. \& Shiio, I. (1982). Methionine biosynthesis in Brevibacterium flavum: properties and essential role of $O$-acetylhomoserine sulfhydrylase. $J$ Biochem 91, 1163-1171.

Parsot, C., Saint Girons, I. \& Cohen, G. N. (1987). Enzyme specialization during the evolution of amino acid biosynthetic pathway. Microbiol Sci 4, 258-262.

Pigg, C. J., Spence, K. D. \& Parks, L. W. (1962). Methionine biosynthesis in yeast. Arch Biochem Biopbys 97, 491-496.

Richaud, C., Mengin-Lecreulx, D., Pochet, S., Johnson, E. J., Cohen, G. N. \& Marlière, P. (1993). Directed evolution of biosynthetic pathways: recruitment of latent cysteine thioethers for constructing the cell wall of Escherichia coli. $J$ Biol Chem 268, 26827-26835.

Schelenz, H. J., Gunther, E., Herrmann, H. \& Schatte, L. (1986). Transductional analysis of the cysII region of Pseudomonas aeruginosa. J Basic Microbiol 26, 55-63.

Sharpe, G. S. (1984). Broad host range cloning vectors for Gramnegative bacteria. Gene 29, 93-102.

Simon, M. \& Hong, J. S. (1983). Direct homocysteine biosynthesis from O-succinylhomoserine in Escherichia coli: an alternate pathway that bypasses cystathionine. J Bacteriol 153, 558-561.

Tso, J. Y., Zalkin, H., Van Cleemput, M., Yanofsky, C. \& Smith, J. M. (1982). Nucleotide sequence of Escherichia coli purF and deduced amino acid sequence of glutamine phosphoribosylpyrophosphate amidotransferase. J Biol Chem 257, 3525-3531.

West, S. E. H. \& Iglewski, B. H. (1988). Codon usage in Pseudomonas aeruginosa. Nucleic Acids Res 16, 9323-9335.

Wiebers, J. L. \& Garner, M. R. (1967). Acyl derivatives of homoserine as substrates for homocysteine synthesis in Neurospora crassa, yeast and Escherichia coli. J Biol Chem 242, 5644-5649.

Yamagata, S. (1989). Roles of O-acetyl-L-homoserine sulfhydrylases in microorganisms. Biocbimie 71, 1125-1143.

Yanisch-Perron, C., Viera, J. \& Messing, J. (1985). Improved M13 phage cloning vectors and host strains: nucleotide sequences of the M13mp18 and pUC19 vectors. Gene 33, 103-119.

Received 6 July 1994; revised 17 October 1994; accepted 19 October 1994. 